\title{
Investigation of the Effect of Crumb Rubber Powder and Warm Additives on Moisture Resistance of SMA Mixtures
}

\author{
Hassan Ziari, ${ }^{1}$ Hassan Divandari ${ }^{(D)},{ }^{2}$ Seyed Mohammad Seyed Ali Akbar, ${ }^{1}$ \\ and Seyed Mohsen Hosseinian $\mathbb{D}^{1}$ \\ ${ }^{1}$ Department of Civil Engineering, Iran University of Science and Technology (IUST), Tehran, Iran \\ ${ }^{2}$ Department of Civil Engineering, Nowshahr Branch, Islamic Azad University, Nowshahr, Iran \\ Correspondence should be addressed to Hassan Divandari; h.divandari@gmail.com
}

Received 24 December 2020; Revised 4 March 2021; Accepted 31 March 2021; Published 14 April 2021

Academic Editor: Jiangfeng Dong

Copyright (C) 2021 Hassan Ziari et al. This is an open access article distributed under the Creative Commons Attribution License, which permits unrestricted use, distribution, and reproduction in any medium, provided the original work is properly cited.

\begin{abstract}
Stone matrix asphalt (SMA) mixtures are one of the most resistant types of asphalt mixtures known to date that the bulk load is borne by the aggregate skeleton. In this research, the effect of crumb rubber powder (CRP), Vestenamer polymer, and warm additives, including Sasobit, ZycoTherm, and a porous and warm mix asphalt (PAWMA), was investigated on the moisture resistance of SMA mixtures. A segregation test was performed to determine the tendency of the polymer to separate from modified polymer bitumen under storage conditions. Also, a drain down sensitivity test was conducted to explore the bleeding phenomena and drain down of SMA mixtures. Finally, a boiling water test, as well as an indirect tensile strength (ITS) test, was applied to examine the sensitivity of mixtures to moisture. The segregation test results indicated that by the use of Vestenamer polymer, a conventional (low speed) mixer can be used instead of using a high-speed mixer, and this will be very important in the cost of rubber bitumen production. The drain down test results showed that cellulose fibers prevented the bitumen bleeding of SMA mixtures. Also, the results of the boiling water test indicated that CRP samples containing ZycoTherm had the highest moisture resistance compared to the other warm additives. Among various mixtures, 8\% CRP-modified samples containing ZycoTherm resulted in the lowest amount of stripping in SMA mixtures, even more than the base sample. The ITS test results illustrated that the use of CRP, Vestenamer polymer, and warm additives had a significant effect on the ITS amounts of mixtures. Moreover, the samples containing ZycoTherm had the highest tensile strength ratio (TSR) compared to the other SMA samples.
\end{abstract}

\section{Introduction}

In recent years, the use of recycled polymers instead of pure polymers has risen significantly with the aim of adapting to the environment and reducing costs as a suitable way to dispose waste. The use of crumb rubber powder (CRP) from rubber recycling as a bitumen additive helps to dispose rubber waste and reduce road construction costs $[1,2]$. The characteristics of bitumen modified with CRP depend on various factors, including CRP particle size, chemical and physical characteristics of bitumen, and processing parameters (e.g., time, applied shear stress, and temperature) $[3,4]$. The use of CRP also improves the characteristics of asphalt mixtures and bitumen, such as reducing the production and maintenance costs of asphalt, increasing the resistance against permanent deformation [5], and improving thermal resistance and fatigue life $[6,7]$. Also, by increasing the bitumen viscosity at a high temperature, it increases the rutting resistance [8]. Despite the positive impact of CRP on the fatigue and rutting performances of asphalt samples, the study of moisture resistance of rubber asphalt samples has always been regarded as a significant challenge, and the impact of moisture susceptibility on rubber asphalt samples has been less investigated [9]. Nowadays, studies have indicated that asphalt samples comprising modified bitumen with CRP were more sensitive to moisture $[10,11]$.

Moisture damage is a process caused by the infiltration of water into the asphalt, which can lead to various distresses in pavement and also eliminate the adhesion between aggregate and bitumen and cohesion in bitumen membrane and, as a result, cause stripping of asphalt mixtures $[12,13]$. Today, 
the necessity to apply novel substances in the asphalt mixture structure is felt in order to decrease damages caused by moisture because of the development of the pavement systems, increase traffic amount and high weight trucks, and further harsh environmental conditions [14-18].

Stone matrix asphalt (SMA) is a combination of gapgradated aggregate (a huge part of coarse aggregate) and a high percentage of bitumen, which is one of the most resistant types of asphalt mixtures known to date [19]. SMA was produced in Germany in 1960 and, nowadays, is applied in heavy traffic situations. The chemical and physical characteristics of SMA ingredients depend on the source of the production, but the mechanical properties of the mixtures are significantly dependent on SMA mix design $[20,21]$.

SMA, which is one of the most resistant types of asphalt mixtures known to date, performs the load transfer process through direct stone-on-stone contact. In order to provide this contact in SMA mixtures, the gap-gradated granulation should be used to construct this type of mixture, which will greatly increase the amount of air voids in these mixtures $[19,22]$. Excessively increasing the air voids of asphalt mixtures will significantly reduce their strength. As a result, in order to prevent this problem, the extra air voids should be filled with bitumen mortar, filler, or additives, so that the percentage of air voids reaches the allowable value. The high value of bitumen and the gap-gradated structure in SMA samples are the principal causes of bleeding, in which polymers and fibers are used to solve this problem [23]. The first purpose of using polymers and fibers is to prevent bleeding and to ensure the integrity of these samples, and the second purpose is to enhance the resistance and stiffness of samples to distresses [24-26].

Since in asphalt mixtures with the aggregate skeleton, the percentage of air voids is low and the bitumen content is high, the probability of aggregate stripping phenomenon is low if the bleeding amount of mixtures is insignificant. On the other hand, the adhesion of bitumen to aggregates and the chemical and physical characteristics of bitumen components change over time under the influence of heat and aging processes. As bitumen gradually ages over time, it becomes harder and more brittle, resulting in a loss of adhesion. Therefore, in order to achieve long-term service of bitumen and increase its durability, the processes of aging, oxidation, and other physical and chemical changes should be eliminated or decreased. Reducing the percentage of air voids and increasing the bitumen membrane around the aggregates in SMA mixtures delays the oxidation and aging processes and makes the asphalt pavements more durable. On the other hand, if a suitable additive is not used as a modifier for the mixtures, the possibility of bleeding in SMA mixtures is very high and the bitumen may separate from the aggregates under loading conditions. For this reason, additives are used to modify bitumen and enhance its characteristics.

Researchers in the asphalt industry are always trying to decrease the mixing and compaction temperatures of asphalt mixtures. The need to heat bitumen and aggregates to temperatures sometimes above 150 degrees in order to make asphalt mixtures is accompanied by various problems such as increasing the cost of asphalt construction, producing more harmful substances for the environment and the difficulty of asphalt construction in the cold seasons of the year. Recent studies in this area have led researchers to produce and evaluate warm asphalt mixtures (WMAs) [27]. Now, in different countries of the world, especially in countries where energy production is being performed at a high cost, the need to use new technologies seems necessary in order to reduce energy consumption. Therefore, WMA is a new technology that reduces the mixing and compaction temperatures of hot mix asphalt (HMA) using additives. Reducing energy consumption and greenhouse gas emissions have made WMA technology a hot topic in the asphalt industry [28-30]. Using this technology with SMA mixtures and CRP can significantly reduce the cost of construction and maintenance of new roads.

Shivaprasad et al. investigated the effect of Sasobit on moisture resistance of SMA mixtures modified with CRP and indicated that no considerable differences were observed in mixtures [31]. Also, Cao and Liu concluded the same results and showed that Sasobit did not considerably increase the moisture sensitivity of SMA mixtures containing CRP [32]. However, limited research studies have been performed on evaluating the effect of ZycoTherm and a porous and warm mix asphalt (PAWMA) on moisture resistance of SMA mixtures modified with CRP. Ameli et al. explored the influence of Sasobit and ZycoTherm on the performance of SMA mixtures containing styrene-butadiene rubber and concluded that both of the WMA additives enhanced the moisture resistance of mixtures; however, Sasobit additive had a better influence than ZycoTherm [33]. Yousefi et al. investigated the performance of asphalt mixtures containing WMA additives, including PAWMA, Sasobit, Kaowax, and zeolite, and indicated that only PAWMA among the other WMA additives reduced the resistance of mixtures to damages caused by moisture. Moreover, they concluded that samples containing PAWMA and reclaimed asphalt pavement had the highest moisture resistance [34].

Katman et al. evaluated the permanent deformation of SMA using crumb rubber and Vestenamer polymer and indicated that the resistance to permanent deformation was improved by the application of these materials [35]. Solaimanian et al. found that combining 5\% mesh-14 ground tire rubber and Vestenamer increased the high-temperature bitumen one grade and the failure strain at low temperatures, and the repeated shear test at constant sample height illustrated an improved resistance to rutting [36]. Yadollahi and Sabbagh Mollahosseini showed that the use of Vestenamer polymer in CRP-modified asphalt reduced the creep stiffness of bitumen and also increased the low-temperature crack resistance [37].

As illustrated in previous studies, many research studies have been performed on the effect of Vestenamer polymer on various distresses of asphalt; however, limited studies have been conducted on moisture behavior and storage stability of CRP-modified SMA mixtures. Moreover, limited research studies have been performed on the effect of WMA 
additives on segregation degree and bitumen bleeding phenomena in SMA mixtures containing CRP.

The principal aim of the present research was to explore the influence of CRP, Vestenamer polymer, and warm additives, including Sasobit, ZycoTherm, and PAWMA, on the moisture resistance of SMA samples. A segregation test was also conducted to determine the tendency of the polymer to separate from modified polymer bitumen under storage conditions. Moreover, a drain down sensitivity test was performed to explore the bleeding phenomena and drain down of SMA samples. Finally, a boiling water test, as well as an indirect tensile strength (ITS) test, was applied to examine the sensitivity of samples to moisture damage.

\section{Experimental Design}

2.1. Aggregate. The applied aggregate in this study was limestone. The grading of aggregate was based on ASTM standards that the maximum and nominal sizes of aggregate are $1.9 \mathrm{~cm}$ and $1.25 \mathrm{~cm}$, respectively. The grading structure is displayed in Figure 1. Also, the physical characteristics of aggregate applied are given in Table 1.

2.2. Bitumen. In this study, bitumen with $60 / 70$ penetration grade was used as base bitumen and prepared from the Pasargad oil refinery, the characteristics of which are illustrated in Table 2.

2.3. Additives. In this research, bitumen has been used to prepare mixtures containing CRP as well as WMA rubber mixtures. To make rubber mixtures, the bitumen has been modified with CRP passing through the $0.150 \mathrm{~mm}$ sieve in three weight percentages of $8 \%, 12 \%$, and $16 \%$. Also, to make warm rubber asphalt mixtures, CRP-modified bitumen has been modified using 2\% Sasobit, 0.1\% ZycoTherm, and 0.3\% PAWMA additives by the weight of bitumen. In addition, $5 \%$ Vestenamer polymer by the weight of CRP was applied to facilitate asphalt modification with CRP. Also, the purpose of using this additive was to investigate the possibility of removing the high shear mixer using the segregation test. The additive amounts were selected according to the previous study [37-42]. On the other hand, Sasobit and ZycoTherm were used to decrease the mixing and compaction temperatures of asphalt samples. ZycoTherm was also applied to enhance the moisture resistance of samples at the same time as an antistripping agent. PAWMA was utilized to facilitate the construction operation by reducing the viscosity of asphalt mixtures during asphalt production and increase the efficiency of asphalt mixtures. The abbreviations for naming different combinations of mixtures are presented in Table 3. Moreover, in this study, cellulose fibers were used to make samples to prevent bleeding and increase resistance. $0.3 \%$ cellulose fiber by the weight of total asphalt mixture was used according to NCHRP report 425 . In addition, the gradation of CRP, as well as the properties of Vestenamer polymer, Sasobit, ZycoTherm, PAWMA, and cellulose fibers, is presented in Tables 4-9, respectively.

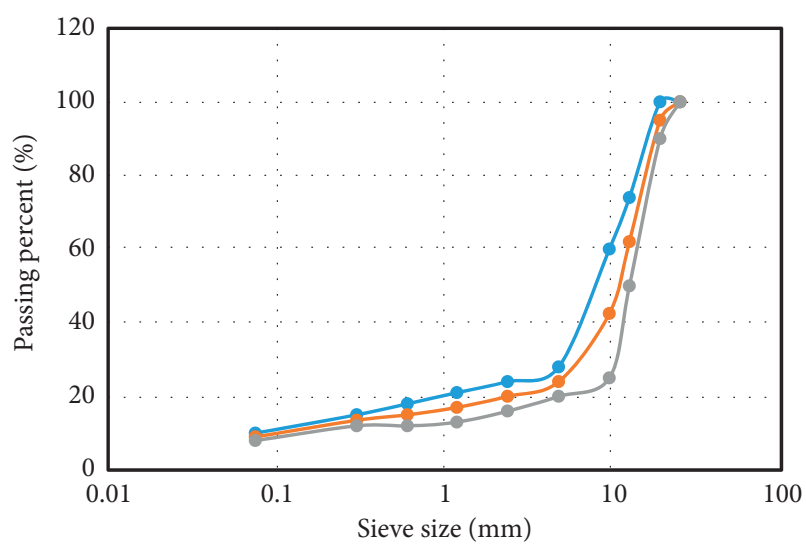

Figure 1: The aggregate grading applied in this research.

2.4. Sample Preparation. Different percentages of CRP and $0.5 \%$ Vestenamer were added to the preheated bitumen at $170^{\circ} \mathrm{C}$ and mixed for 90 min with a conventional shear mixer at $300 \mathrm{rpm}$ shearing speed. In order to provide mixtures containing Sasobit and ZycoTherm, the additives were gradually added during the mixing process to produce a homogeneous mixture and were mixed with a stirrer at a low speed for 20 minutes. Moreover, for providing mixtures containing PAWMA, the mixing time of this additive with pure bitumen was at least 1 hour. The cellulose fibers were also crushed before mixing with the aggregate to reach the cotton state; then, it was added to the aggregate when making asphalt samples.

2.5. Asphalt Mix Design. According to ASTM D5581, the Marshall mix design method was conducted in this research in order to specify the optimal bitumen amount. The optimal bitumen amount for mix design was determined based on the average of the three bitumen amounts corresponding to $4 \%$ air void, the greatest specific gravity, and the greatest Marshall strength. The optimal bitumen amount for the production of SMA mixtures was specified to be $6 \%$.

\subsection{Tests}

2.6.1. Segregation Test. This experiment describes a method for determining the tendency of a polymer to separate from modified polymer bitumen under storage conditions, according to ASTM D7173. In this method, about 50 grams of polymer-modified bitumen is first poured into an aluminum tube with a diameter of $25 \mathrm{~mm}$ and a length of $125-140 \mathrm{~mm}$. It is then placed vertically in an oven at $163 \pm 5^{\circ} \mathrm{C}$ for 48 hours. The sample is then placed vertically in the freezer at a temperature of $-10 \pm 10^{\circ} \mathrm{C}$ for about 4 hours, after which the tube containing the sample is cut into 3 approximately equal parts; the middle part is set aside, and the upper and lower parts are placed separately in a $100 \mathrm{ml}$ container into an oven at $163^{\circ} \mathrm{C}$ for 30 minutes until completely lubricated. Finally, a softening point test is conducted for these two parts, and the results are compared with each other $[43,44]$. 
TABle 1: The physical characteristics of aggregate.

\begin{tabular}{lccc}
\hline Characteristics & Standards & Results & Regulation limits \\
\hline Special gravity (coarse grains) & & 2.69 & - \\
$\quad$ Apparent & ASTM: C127 & 2.64 & - \\
$\quad$ Effective & & 2.61 & \\
$\quad$ Bulk & & & \\
Specific gravity (fine grains) & & 2.68 & - \\
$\quad$ Apparent & ASTM: C128 & 2.63 & - \\
Effective & & 2.61 & - \\
$\quad$ Bulk & ASTM: D854 & 2.55 & - \\
Specific gravity (filler) & ASTM: D5821 & 94 & Minimum 10 \\
Flat and elongated particles (\%) & ASTM: C127 & 0.8 & Maximum 2 \\
Water absorption (\%) & ASTM: D4791 & 9 & Maximum 15 \\
Needle and flake particles & ASTM: C88 & 7 & Maximum 15 \\
Sodium sulfate soundness (\%) & ASTM: C131 & 22.3 & Maximum 30 \\
Los Angeles abrasion (\%) & & & \\
\hline
\end{tabular}

TABle 2: The characteristics of base bitumen.

\begin{tabular}{lcc}
\hline Characteristics & Standard & Base bitumen \\
\hline Density in $25^{\circ} \mathrm{C}$ & ASTM: D70 & 1.03 \\
Los on heating $(\%)$ & ASTM: D1754 & 0.75 \\
Ductility $(\mathrm{cm})$ & ASTM: D113 & 102 \\
Flash and fire point $\left({ }^{\circ} \mathrm{C}\right)$ & ASTM: D92 & 305 \\
Solubility $(\%)$ & ASTM: D2042 & 99.5 \\
Softening point $\left({ }^{\circ} \mathrm{C}\right)$ & ASTM: D36 & 54 \\
Degree of penetration $(0.1 \mathrm{~mm})$ & ASTM: D5 & 64 \\
\hline
\end{tabular}

TABLE 3: The combinations of mixtures constructed.

\begin{tabular}{|c|c|c|c|c|}
\hline \multirow{2}{*}{ Combination } & \multicolumn{4}{|c|}{ Additive types and percentages } \\
\hline & CRP & Sasobit & ZycoTherm & PAWMA \\
\hline Base & - & - & - & - \\
\hline CRP8 + V & 8 & - & - & - \\
\hline $\mathrm{CRP} 12+\mathrm{V}$ & 12 & - & - & - \\
\hline CRP16+V & 16 & - & - & - \\
\hline CRP8 S + V & 8 & 2 & - & - \\
\hline CRP12 S + V & 12 & 2 & - & - \\
\hline CRP16 S + V & 16 & 2 & - & - \\
\hline CRP8 Z+V & 8 & - & 0.1 & - \\
\hline CRP12 Z+V & 12 & - & 0.1 & - \\
\hline CRP16 Z + V & 16 & - & 0.1 & - \\
\hline CRP8 P + V & 8 & - & - & 0.3 \\
\hline CRP12 P + V & 12 & - & - & 0.3 \\
\hline CRP16 P + V & 16 & - & - & 0.3 \\
\hline
\end{tabular}

TABle 4: Applied grading of CRP used.

\begin{tabular}{lr}
\hline Sieve size $(\mathrm{mm})$ & Percentage of passing \\
\hline 0.150 & 100 \\
Pan & 0 \\
\hline
\end{tabular}

TABLE 5: The properties of Vestenamer polymer used.

\begin{tabular}{lccccc}
\hline Color & Density at $25^{\circ} \mathrm{C}\left(\mathrm{g} / \mathrm{cm}^{3}\right)$ & Melting point $\left({ }^{\circ} \mathrm{C}\right)$ & Form & Glass transition temperature $\left({ }^{\circ} \mathrm{C}\right)$ & Physical state \\
\hline White & 0.91 & 54 & Granular & -65 & Solid \\
\hline
\end{tabular}

TABle 6: The properties of Sasobit used.

\begin{tabular}{lccccc}
\hline Color & Density at $25^{\circ} \mathrm{C}\left(\mathrm{g} / \mathrm{cm}^{3}\right)$ & Melting point $\left({ }^{\circ} \mathrm{C}\right)$ & Flash point $\left({ }^{\circ} \mathrm{C}\right)$ & Viscosity $\left(135^{\circ} \mathrm{C}\right)(\mathrm{Pa} \mathrm{s})$ & Penetration at $65^{\circ} \mathrm{C}(0.1 \mathrm{~mm})$ \\
\hline White & 0.94 & 99 & 285 & 0.012 & 7 \\
\hline
\end{tabular}


TABLE 7: The properties of ZycoTherm used.

\begin{tabular}{lcccc}
\hline Color & Physical state & Specific gravity $\left(\mathrm{g} / \mathrm{cm}^{3}\right)$ & Flash point $\left({ }^{\circ} \mathrm{C}\right)$ & Viscosity $(\mathrm{Pa} \mathrm{s})$ \\
\hline Pale yellow & Liquid & 0.97 & 80 & $1-3$ \\
\hline
\end{tabular}

TABLE 8: The properties of PAWMA used.

\begin{tabular}{lcccc}
\hline Color & $\mathrm{pH}$ & Specific gravity $\left(\mathrm{g} / \mathrm{cm}^{3}\right)$ & Flash point $\left({ }^{\circ} \mathrm{C}\right)$ & Solubility in water \\
\hline Yellow & Neutral & 0.94 & 167 & Insoluble \\
\hline
\end{tabular}

TABLE 9: The properties of cellulose fibers used.

Cellulose fiber percentage Average fiber length $(\mathrm{mm})$ Average fiber thickness $(\mathrm{mm}) \quad \mathrm{pH}$-value $(5 \mathrm{~g} / 100 \mathrm{ml}) \quad$ Specific gravity $\left(\mathrm{g} / \mathrm{cm}^{3}\right)$

\begin{tabular}{lllll}
\hline $80 \pm 5$ & 1.1 & 0.045 & $7.5 \pm 1$ & $0.5 \pm 0.05$
\end{tabular}

2.6.2. Drain Down Test. The determination of drain down amount in an uncompacted sample at the optimal bitumen amount was performed according to AASHTO T305, when the bituminous mixture is kept at a high temperature compared to those faced during the manufacture, transport, storage, and placement of mixtures. The SMA loose mixtures were put in a wire basket fabricated by the use of $6.3 \mathrm{~mm}$ sieve cloth [45].

36 SMA loose mixtures were tested with triplicate mixtures for each SMA design mix, stabilized with or without additives. The SMA loose mixture mass and the initial mass of the pan were specified by nearly $0.1 \mathrm{~g}$. The SMA loose mixture was then placed in a wire basket. The basket was put on the pan, and they were then put in the oven for 1 hour at $175^{\circ} \mathrm{C}$ degrees. They were then removed, and the final mass of the pan was specified approximately $0.1 \mathrm{~g}$. The drain down of the sample was measured as equation 1 :

$$
\text { Drain down }(\%)=100 \frac{C-B}{A} \text {, }
$$

where $A$ presents the mass of the initial total sample $(g), B$ illustrates the mass of the initial pan $(g)$, and $C$ represents the mass of the final pan $(g)$ [46].

2.6.3. Boiling Water Test. The boiling water test was conducted based on the ASTM D3625 standard to examine the moisture sensitivity of asphalt mixtures. About 250 grams of noncondensed samples for 10 minutes based on the standard were put in boiling water and were then returned to room temperature to dry. They were photographed on a white paper after drying the samples, and images were processed to determine the bitumen coating percentage of aggregate. The aim of the boiling water test is to indicate the apparent failure of asphalt samples against moisture susceptibility and water.

2.6.4. ITS Test. The ITS test was performed in this research to examine the moisture behavior of asphalt in accordance with AASHTO T283. So, specimens were first saturated with water for 5 minutes in order to simulate wet conditions. They were then kept for 5-10 minutes without vacuum and in submerged conditions. After they got saturated, they were stored 16 hours in a freezer at -18 degrees. They were then held in a waterbath for 24 hours at 60 degrees, returned to a place with
25 degrees, and held for 24 hours at the same degree [47]. The load was recorded for performing ITS test until rupture, and the amount of ITS $(\mathrm{kPa})$ was then measured [48]:

$$
\text { ITS }=\frac{2 P}{\pi d t}
$$

where $d$ is the specimen diameter $(\mathrm{m}), P$ is the rupture force $(\mathrm{kN})$, and $t$ is the specimen thickness $(\mathrm{m})$. The wet-to-dry tensile strength ratio (TSR) for examining the moisture sensitivity of specimens was measured:

$$
\mathrm{TSR}=\frac{\text { ITS }_{\text {wet }}}{\text { ITS }_{\text {dry }}} \times 100 \%,
$$

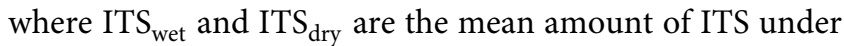
wet and dry conditions, respectively $(\mathrm{kPa})[49,50]$.

\section{Result and Discussion}

3.1. Segregation Test Results. The results of the segregation test for the base and modified mixtures introduced in Table 3 are presented in Table 10. If the difference between the softening point of the lower and upper parts is limited to 2.5 degrees, bitumen is considered thermally stable $[23,51]$.

As is clear from the results, in samples containing CRP with percentages of $8 \%, 12 \%$, and $16 \%$, Vestenamer polymer stabilized the bitumen. As a result, by the use of this polymer, instead of using a high-speed mixer, a conventional (low speed) mixer can be used, and this will be very important in the cost of processing rubber bitumen.

As mentioned, by adding Vestenamer polymer to CRPmodified mixtures, it is possible to use a conventional mixer instead of a high-speed mixer, which has received less attention in the previous studies. Limited research studies have been conducted to investigate the degree of segregation in the process of polymer storage. Fang et al. by investigating the effect of crumb rubber/ethylene vinyl acetate copolymer on asphalt mixture properties indicated that the softening point difference was almost less than 2.5 degrees. Moreover, the compatibility of modifiers and asphalt improved to a certain extent, and the degree of segregation became small and the storage became steady [52], which is in accordance with the results of this research. However, some studies have not conducted this test, and in order to decrease segregation, 
TABLE 10: Segregation test results in various SMA mixtures.

\begin{tabular}{lccc}
\hline Mixtures & $\begin{array}{c}\text { Upper softening } \\
\text { point }\left({ }^{\circ} \mathrm{C}\right)\end{array}$ & $\begin{array}{c}\text { Lower softening } \\
\text { point }\left({ }^{\circ} \mathrm{C}\right)\end{array}$ & $\begin{array}{c}\text { Difference } \\
\left({ }^{\circ} \mathrm{C}\right)\end{array}$ \\
\hline $\mathrm{CRP} 8+\mathrm{V}$ & 62.1 & 63.9 & 1.8 \\
$\mathrm{CRP} 12+\mathrm{V}$ & 67.9 & 69.9 & 2 \\
$\mathrm{CRP} 16+\mathrm{V}$ & 71.7 & 71.9 & 0.2 \\
\hline
\end{tabular}

limited size of fine crumb rubber was applied $[5,53]$. Hosseinnezhad et al. concluded that surface-activated rubber and microwave-activated crumb rubber-modified asphalt had lower segregation compared with those of conventional crumb rubber-modified asphalt, indicating that the first two treatments were very effective to improve the compatibility of rubber and asphalt matrix [43].

3.2. Drain Down Test Results. The drain down test was performed according to AASHTO T305, and the results for various combinations are shown in Figure 2.

The results of the drain down test for bitumen bleeding showed that only the fiber-free base mixture had more than $0.3 \%$ drain down, and the rest of the mixtures were within the allowable range. Also, by increasing the amount of CRP, the bitumen bleeding decreased. As can be seen, cellulose fibers prevented the bitumen bleeding of the mixtures, which indicates the high ability of cellulose fibers to increase the bitumen resistance against drain down in SMA mixtures.

Limited studies have been performed on the bitumen bleeding of mixtures by the use of cellulose fibers. Ziari et al. showed that cellulose fibers highly reduced the bitumen bleeding of mixtures, which is in accordance with the results of this study [54]. However, Beena and Bindu focused on the effect of additives such as coir, sisal, banana fibers (natural fibers), waste plastics (waste material), and polypropylene (polymer) on the drain down characteristics of SMA mixtures. They revealed that fiber stabilizers were more effective in reducing the drain down of SMA mixture [45]. Moreover, several studies have been conducted to use chemical additives to improve the storage stability of crumb rubbermodified asphalt. In one study, reactive polyoctenamer and cross-linking agents were applied to improve the anchoring of crumb rubber in asphalt and improve the storage stability of crumb rubber-modified asphalt [55]. In another study, SBS and sulfur were used as modifiers to improve the storage stability and tenacity of crumb rubber-modified asphalt [56]. Also, Leng et al. in their research found that the incorporation of polyethylene terephthalate-based additives to crumb rubber-modified asphalt improved the storage stability of crumb rubber-modified binder [57]. Moreover, Yu et al. performed microwave treatment on crumb rubber before mixing it with asphalt. They showed that asphalt containing treated rubber improved storage stability compared to specimens containing nontreated rubber [58].

3.3. Boiling Water Test Results. The results of the image processing of noncondensed asphalt samples after the boiling water test are shown in Figure 3. The pictures showed that yellow pixels in CRP-modified asphalt samples

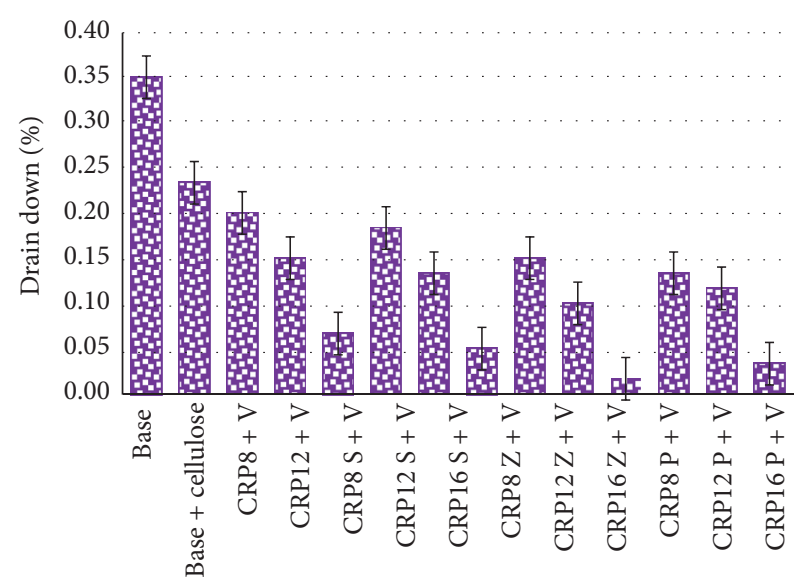

Figure 2: Drain down test results for different SMA mixtures.

increased compared to the base sample, and as a result, the stripping rate of SMA mixtures increased. In addition, Figure 4 presents the amount of bitumen coating on the aggregate surface that by comparing the pictures in Figure 3 and the results of Figure 4, it is evident that bitumen modification with Sasobit and PAWMA in CRP samples increased the moisture susceptibility of asphalt mixtures. However, CRP samples containing ZycoTherm had the highest moisture resistance, which is in consistent with previous studies [59]. Among various mixtures, CRP8 Z + V resulted in the lowest amount of stripping in asphalt mixtures. Also, some previous studies illustrated that ZycoTherm-modified mixtures had more moisture damage resistance compared to Sasobit WMA and HMA mixtures [40], and some other research studies indicated that adding ZycoTherm to CRP-modified asphalt mixtures improved the moisture resistance of asphalt mixtures [60], the results of which are in accordance with the results of this study.

3.4. ITS Test Results. The ITS results for various mixtures under dry and wet conditions were examined in this research. As shown in Figure 5, with the cohesion loss of asphalt mixtures due to the exposure of the samples to the moisture, the ITS amounts of the samples in wet conditions were reduced compared to those of samples in dry conditions. The ITS amounts in both wet and dry conditions were increased by modifying the properties of bitumen with CRP as well as warm additives. By adding CRP to the bitumen, the cohesion and adhesion of mixtures were increased and caused it to reach a higher moisture resistance over the unmodified mixture. The results also showed that by increasing the percentage of CRP from $8 \%$ to $16 \%$, the ITS amount of asphalt mixtures increased. The reason for this is the enhancement in stiffness and adhesion of bitumen, leading to an improvement in the resistance. Also, the ITS amount of asphalt mixtures increased slightly with the addition of warm additives.

Figure 6 illustrates the TSR amounts of samples. As is clear, by increasing the CRP amount from $8 \%$ to $16 \%$, the sensitivity of mixtures to moisture was increased; however, the samples containing ZycoTherm had a higher TSR than all 


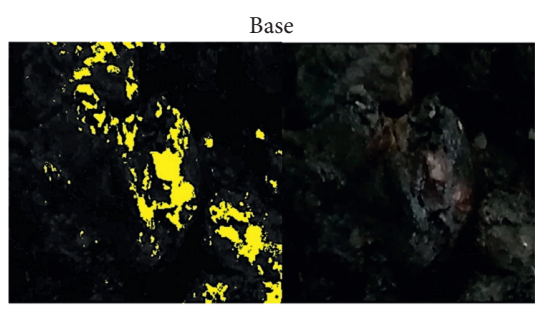

$\mathrm{CRP} 12+\mathrm{V}$

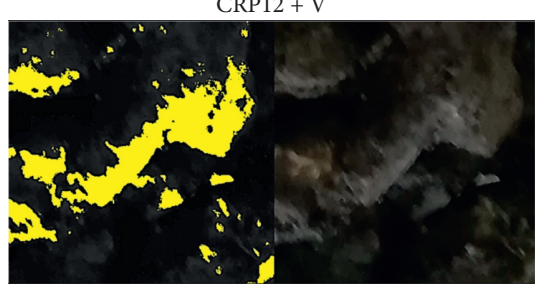

CRP8 $\mathrm{S}+\mathrm{V}$

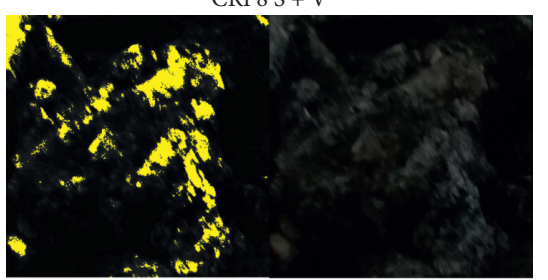

$\mathrm{CRP} 16 \mathrm{~S}+\mathrm{V}$

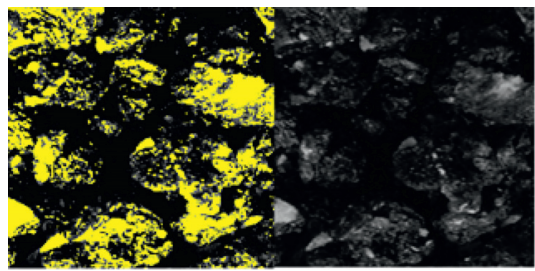

$\mathrm{CRP} 12 \mathrm{Z}+\mathrm{V}$

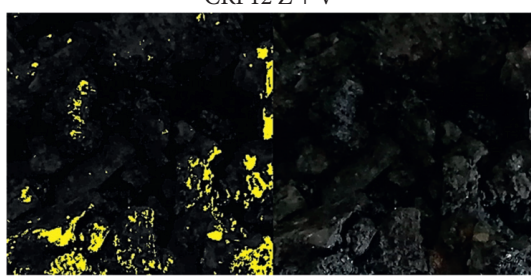

$\mathrm{CRP} 8 \mathrm{P}+\mathrm{V}$

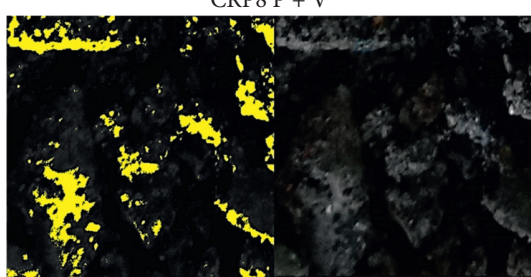

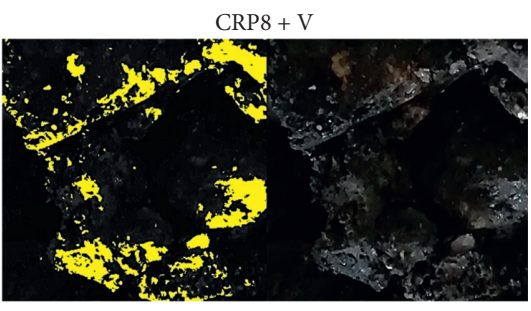

$\mathrm{CRP} 16+\mathrm{V}$

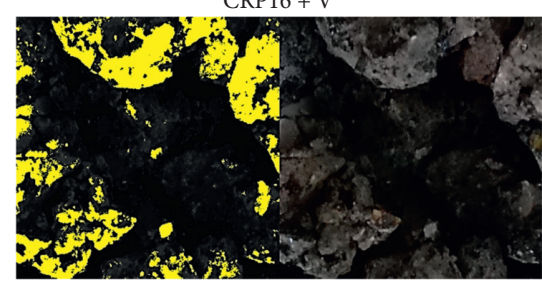

$\mathrm{CRP} 12 \mathrm{~S}+\mathrm{V}$

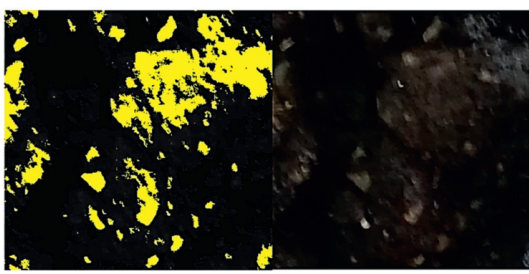

CRP8 Z + V

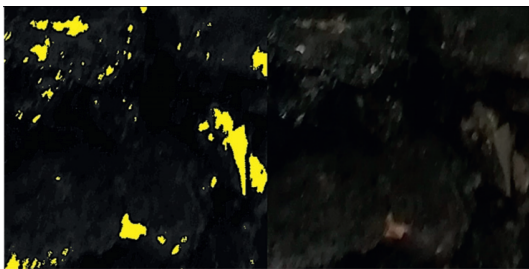

$\mathrm{CRP} 16 \mathrm{Z}+\mathrm{V}$

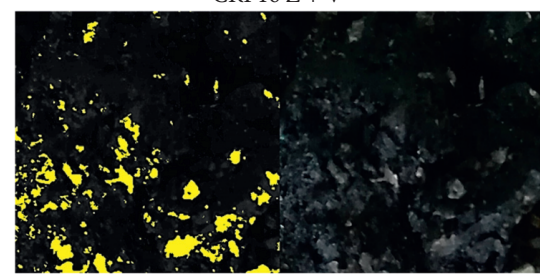

CRP12 P + V
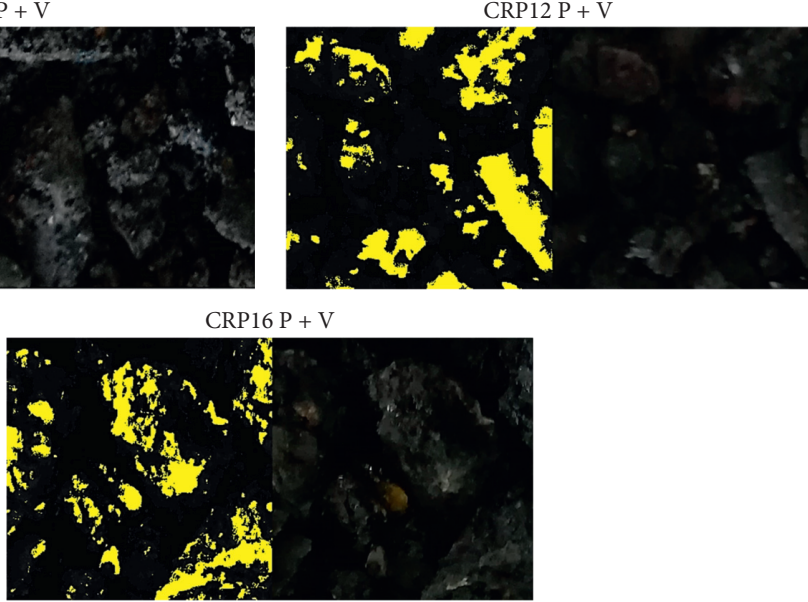

FIgURE 3: The image processing of samples after the boiling water test. 


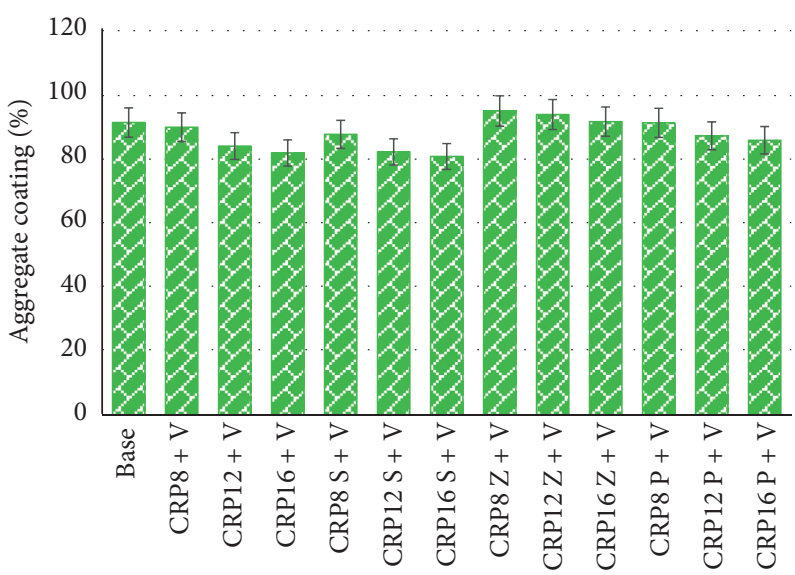

FIGURE 4: Aggregate coating in samples after the boiling water test.

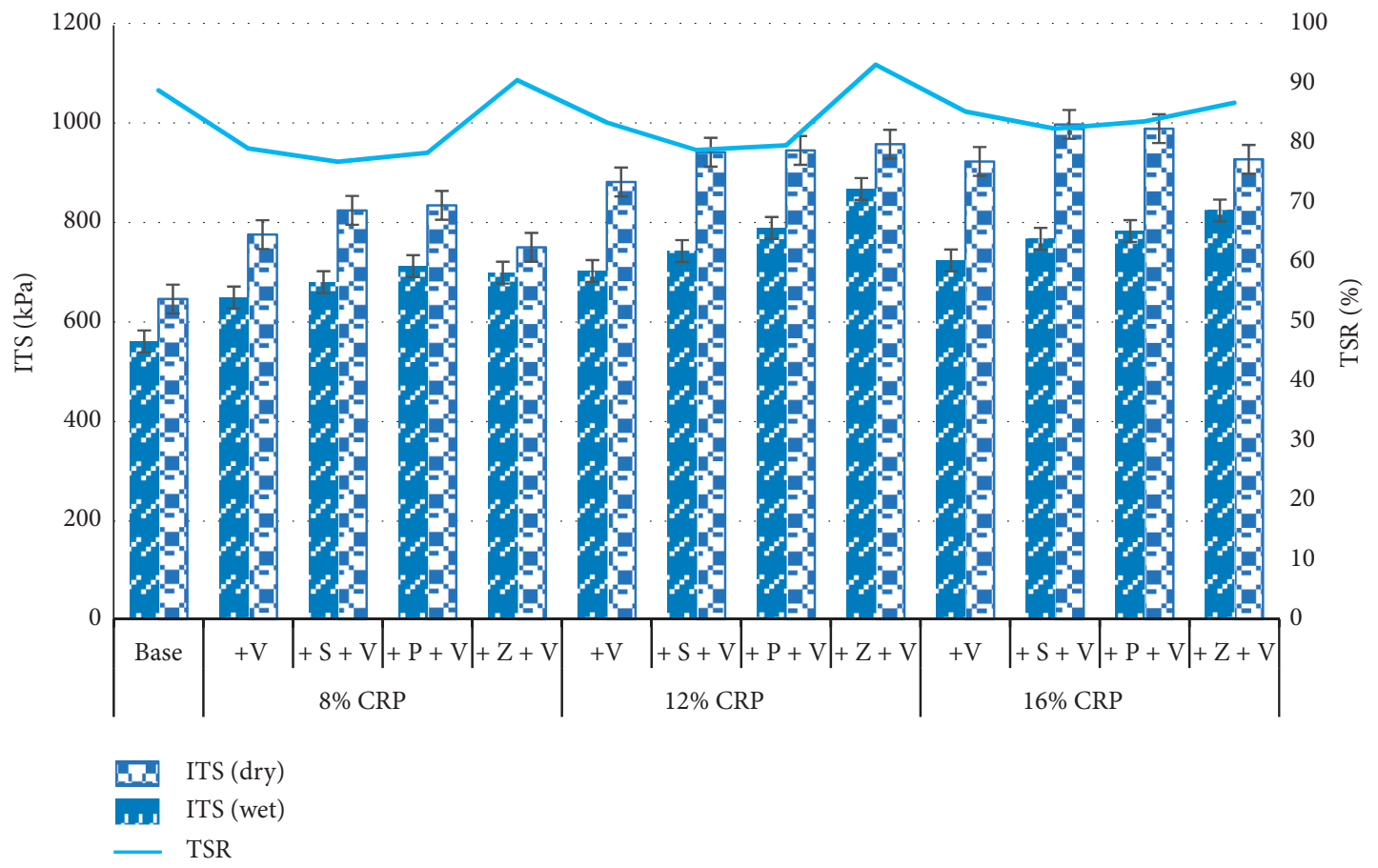

FIGURE 5: ITS and TSR of various mixtures.

the samples, so that the TSR amount of CRP8 $\mathrm{Z}+\mathrm{V}$, CRP12 $\mathrm{Z}+\mathrm{V}$, and CRP16 $\mathrm{Z}+\mathrm{V}$ combinations was $7.39 \%, 4.39 \%$, and $2.42 \%$ higher than the base mixture, respectively. All results showed values greater than $75 \%$ for resistance to moisture sensitivity. This can be due to the high percentage of bitumen in these SMA mixtures, which surrounds the aggregates like a membrane and prevents moisture from penetrating them. According to the results, it can be seen that the base sample was more resistant to moisture than samples containing CRP with Sasobit and PAWMA additives.

According to Figure 7, the absolute slope value of the TSR curve in samples containing ZycoTherm was lower than other warm additives, which shows that the rate of TSR decrease by increasing the CRP contents in samples containing ZycoTherm was less than the rest. In other words, the TSR of ZycoTherm-modified samples was less sensitive to increasing the CRP contents. On the other hand, due to the high value of $R^{2}$ in the samples containing ZycoTherm, it can be concluded that the rate of reduction of the TSR value was linear. Moreover, samples containing PAWMA had the highest slope, which indicates that PAWMA was more sensitive to increasing the CRP amounts. Therefore, PAWMA is not suitable for asphalt mixtures containing high CRP amounts, and it is better to use ZycoTherm in order to prevent moisture sensitivity of SMA mixtures.

As illustrated, the TSR value of asphalt samples decreased by increasing the amount of CRP, which has been confirmed in previous studies [61]. However, the results of some studies have shown that ZycoTherm additive has improved the moisture resistance of asphalt samples containing rubber powder [60], which is in consistent with the results of this study. Moreover, Ayazi et al. indicated that 


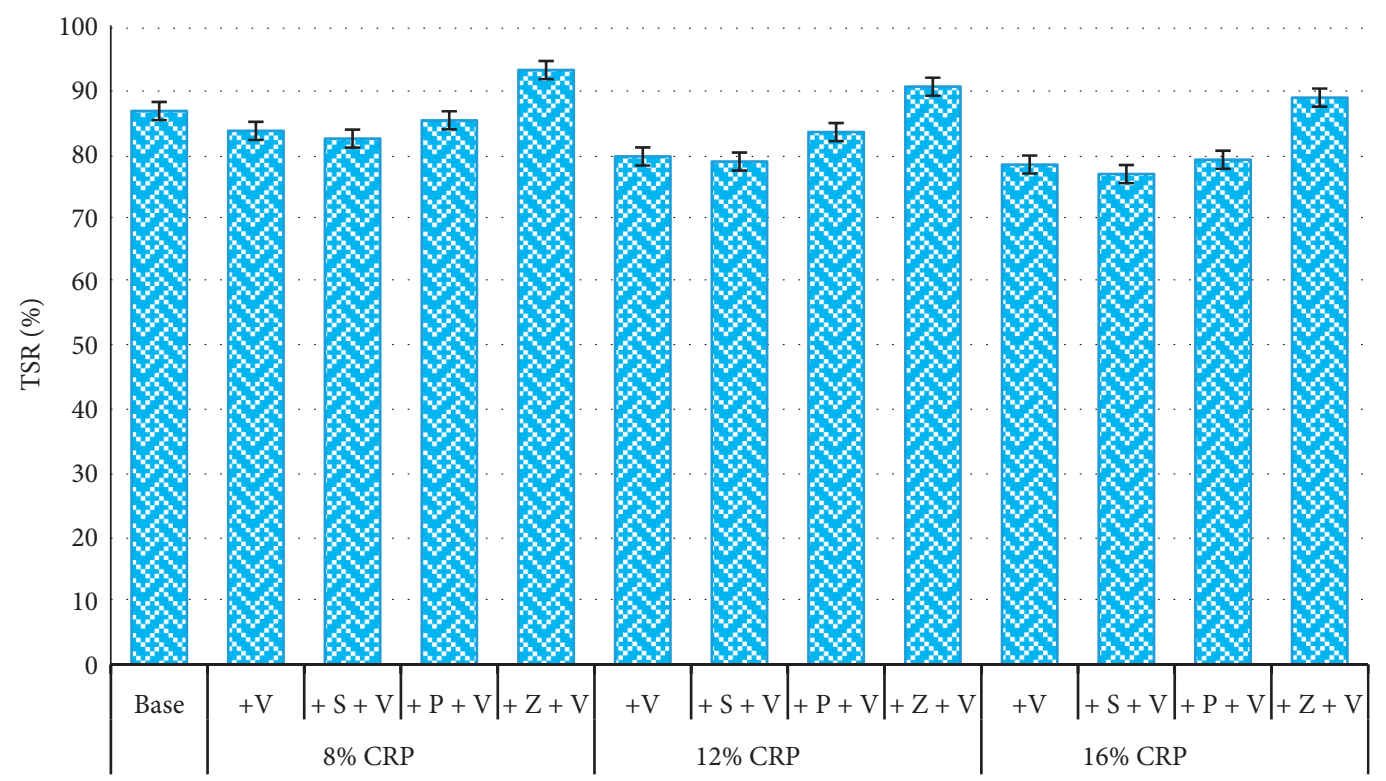

FIGURE 6: TSR results of various mixtures in the ITS test.

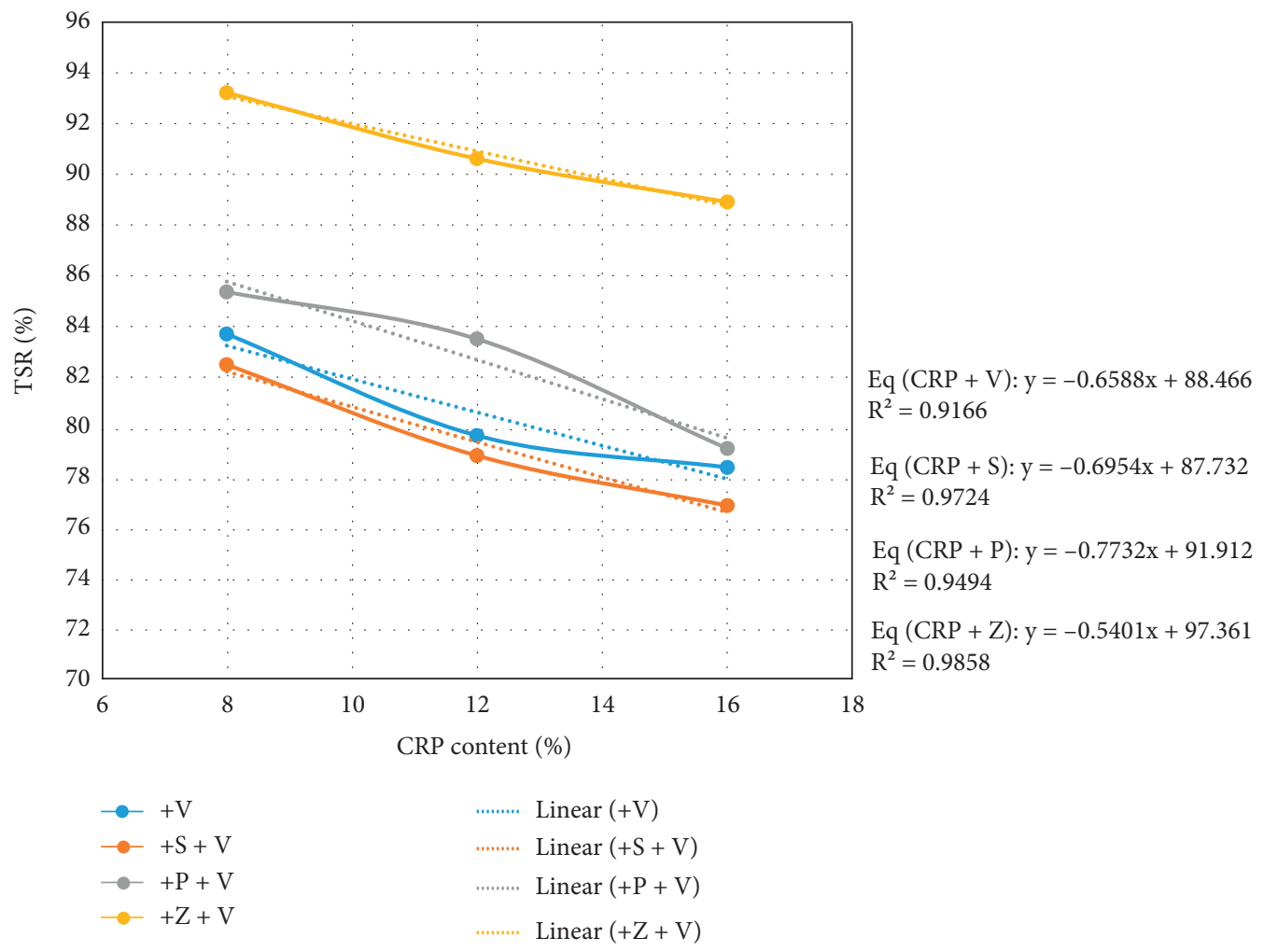

FIGURE 7: TSR variations in different CRP contents for various mixtures.

ZycoTherm mixtures had more resistance to moisture damage than Sasobit WMA and HMA samples [40], which is in accordance with the results of this research.

\section{Conclusions}

In this study, the moisture behavior of asphalt mixtures containing CRP was explored using the segregation test, drain down test, boiling water test, and ITS test. The segregation test results showed that by adding Vestenamer polymer to CRP mixtures, it is possible to use a conventional mixer instead of a high-speed mixer. Also, the results of the drain down test indicated that cellulose fibers prevented the bitumen bleeding of the mixtures, which indicates the high ability of cellulose fibers to increase the bitumen resistance against drain down in SMA mixtures. Moreover, the results 
of the boiling water test showed that by increasing CRP content, the stripping amount of mixtures increased, and in each CRP content, ZycoTherm additive had the least stripping rate and Sasobit additive had the highest stripping rate compared to other warm additives. By adding warm additives, except for the ZycoTherm, the TSR value of mixtures reduced; however, samples containing ZycoTherm had the highest TSR value in each CRP content. Finally, this study revealed that the TSR amount of ZycoTherm-modified samples was less sensitive to increasing the CRP contents.

\section{Data Availability}

The data used to support the findings of this study are currently under embargo, while the research findings are commercialized. Requests for data, 3 months after publication of this article, will be considered by the corresponding author.

\section{Conflicts of Interest}

The authors declare that they have no conflicts of interest.

\section{References}

[1] H. Yu, Z. Leng, F. Xiao, and Z. Gao, "Rheological and chemical characteristics of rubberized binders with nonfoaming warm mix additives," Construction and Building Materials, vol. 111, pp. 671-678, 2016.

[2] A. M. Rodríguez-Alloza, J. Gallego, and I. Pérez, "Study of the effect of four warm mix asphalt additives on bitumen modified with $15 \%$ crumb rubber," Construction and Building Materials, vol. 43, pp. 300-308, 2013.

[3] F. Moreno, M. Sol, J. Martín, M. Pérez, and M. C. Rubio, "The effect of crumb rubber modifier on the resistance of asphalt mixes to plastic deformation," Materials \& Design, vol. 47, pp. 274-280, 2013.

[4] B. V. Kök, M. Yilmaz, and A. Geçkil, "Evaluation of lowtemperature and elastic properties of crumb rubber- and SBSmodified bitumen and mixtures," Journal of Materials in Civil Engineering, vol. 25, no. 2, pp. 257-265, 2013.

[5] N. S. Mashaan, A. H. Ali, S. Koting, and M. R. Karim, "Dynamic properties and fatigue life of stone mastic asphalt mixtures reinforced with waste tyre rubber," Advances in Materials Science and Engineering, vol. 2013, Article ID 319259, 9 pages, 2013.

[6] A. R. Pasandín and I. Pérez, "Fatigue performance of bituminous mixtures made with recycled concrete aggregates and waste tire rubber," Construction and Building Materials, vol. 157, pp. 26-33, 2017.

[7] K F. Saberi, M. Fakhri, and A. Azami, "Evaluation of warm mix asphalt mixtures containing reclaimed asphalt pavement and crumb rubber," Journal of Cleaner Production, vol. 165, pp. 1125-1132, 2017.

[8] A. Behnood, "A review of the warm mix asphalt (WMA) technologies: effects on thermo-mechanical and rheological properties," Journal of Cleaner Production, vol. 259, Article ID 120817, 2020.

[9] D. L. Presti, "Recycled tyre rubber modified bitumens for road asphalt mixtures: a literature review," Construction and Building Materials, vol. 49, pp. 863-881, 2013.

[10] I. Pérez and A. R. Pasandín, "Moisture damage resistance of hot-mix asphalt made with recycled concrete aggregates and crumb rubber," Journal of Cleaner Production, vol. 165, pp. 405-414, 2017.

[11] H. Ziari, M. Naghavi, and R. Imaninasab, "Performance evaluation of rubberised asphalt mixes containing WMA additives," International Journal of Pavement Engineering, vol. 19, no. 7, pp. 623-629, 2018.

[12] V. Najafi Moghaddam Gilani, S. M. Hosseinian, H. Behbahani, and G. H. Hamedi, "Prediction and paretobased multi-objective optimization of moisture and fatigue damages of asphalt mixtures modified with nano hydrated lime," Construction and Building Materials, vol. 261, Article ID 120509, 2020.

[13] S. M. Hosseinian, V. N. M. Gilani, P. M. Joobani, and M. Arabani, "Investigation of moisture sensitivity and conductivity properties of inductive asphalt mixtures containing steel wool fiber," Advances in Civil Engineering, vol. 2020, Article ID 8890814, 9 pages, 2020.

[14] M. Nikookar, M. B. Movahhed, J. Ayoubinejad, V. N. M. Gilani, and S. M. Hosseinian, "Improving the moisture sensitivity of asphalt mixtures by simultaneous modification of asphalt binder and aggregates with carbon nanofiber and carbon nanotube," Advances in Civil Engineering, vol. 2021, Article ID 6682856, 11 pages, 2021.

[15] N. Kamboozia, M. Ameri, and S. M. Hosseinian, "Statistical analysis and accident prediction models leading to pedestrian injuries and deaths on rural roads in Iran," International Journal of Injury Control and Safety Promotion, vol. 27, no. 4, pp. 493-509, 2020.

[16] S. M. Hosseinian, V. N. M. Gilani, H. T. Amoli, M. Nikookar, and A. Orouei, "Presentation of analytical methods for better decision making about the most important factor influencing rural accidents," Mathematical Problems in Engineering, vol. 2021, Article ID 5564269, 16 pages, 2021.

[17] N. Kamboozia, M. Ameri, and S. M. Hosseinian, "Statistical analysis and presentation of accident prediction model leading to injuries and deaths of pedestrians in rural roads of Gilan," Journal of Transportation Research, 2020.

[18] N. Kamboozia, M. Ameri, and S. M. Hosseinian, "Investigation of effective factors in the severity of rural road accidents in guilan to determine the most effective factors and provide safety solutions," Road, vol. 29, no. 106, pp. 115-128, 2021.

[19] N. Barazi Jomoor, M. Fakhri, and M. R. Keymanesh, "Determining the optimum amount of recycled asphalt pavement (RAP) in warm stone matrix asphalt using dynamic creep test," Construction and Building Materials, vol. 228, Article ID 116736, 2019.

[20] C. Sangiorgi, P. Tataranni, A. Simone, V. Vignali, C. Lantieri, and G. Dondi, "Stone mastic asphalt (SMA) with crumb rubber according to a new dry-hybrid technology: a laboratory and trial field evaluation," Construction and Building Materials, vol. 182, pp. 200-209, 2018.

[21] S. M. Hosseinian and V. Najafi Moghaddam Gilani, "Analysis of factors affecting urban road accidents in rasht metropolis," ENG Transactions, vol. 1, no. 1, pp. 1-4, 2020.

[22] A. Ameli, R. Babagoli, M. Khabooshani, R. AliAsgari, and F. Jalali, "Permanent deformation performance of binders and stone mastic asphalt mixtures modified by SBS/montmorillonite nanocomposite," Construction and Building Materials, vol. 239, Article ID 117700, 2020.

[23] M. Ameri, R. Mohammadi, M. Vamegh, and M. Molayem, "Evaluation the effects of nanoclay on permanent deformation behavior of stone mastic asphalt mixtures," Construction and Building Materials, vol. 156, pp. 107-113, 2017. 
[24] A. Mokhtari and F. Moghadas Nejad, "Mechanistic approach for fiber and polymer modified SMA mixtures," Construction and Building Materials, vol. 36, pp. 381-390, 2012.

[25] H. Behbahani, S. Nowbakht, H. Fazaeli, and J. Rahmani, "Effects of fiber type and content on the rutting performance of stone matrix asphalt," Journal of Applied Sciences, vol. 9, no. 10, pp. 1980-1984, 2009.

[26] A. Mahani, P. Bazoobandi, S. M. Hosseinian, and H. Ziari, "Experimental investigation and multi-objective optimization of fracture properties of asphalt mixtures containing nanocalcium carbonate," Construction and Building Materials, vol. 285, Article ID 122876, 2021.

[27] H. Yu, Z. Leng, Z. Dong, Z. Tan, F. Guo, and J. Yan, "Workability and mechanical property characterization of asphalt rubber mixtures modified with various warm mix asphalt additives," Construction and Building Materials, vol. 175, pp. 392-401, 2018.

[28] M. R. Pouranian, M. A. Notani, M. T. Tabesh, B. Nazeri, and M. Shishehbor, "Rheological and environmental characteristics of crumb rubber asphalt binders containing nonfoaming warm mix asphalt additives," Construction and Building Materials, vol. 238, Article ID 117707, 2020.

[29] H. Wang, X. Liu, H. Zhang, P. Apostolidis, T. Scarpas, and S. Erkens, "Asphalt-rubber interaction and performance evaluation of rubberised asphalt binders containing nonfoaming warm-mix additives," Road Materials and Pavement Design, vol. 21, no. 6, pp. 1612-1633, 2020.

[30] J. Gong, Y. Liu, Y. Jiang et al., "Performance of epoxy asphalt binder containing warm-mix asphalt additive," International Journal of Pavement Engineering, vol. 22, no. 2, pp. 1-10, 2019.

[31] P. Shivaprasad, F. Xiao, and S. Amirkhanian, Moisture Susceptibility of Polymerized Stone Matrix Asphalt Mixtures Using Warm Mix Asphalt Technologies Using Moist Aggregates, in Testing and Specification of Recycled Materials for Sustainable Geotechnical Construction, ASTM International, West Conshohocken, PA, USA, 2012.

[32] W. Cao and S. Liu, "Performance evaluation of asphalt-rubber stone matrix asphalt mixtures with warm mix asphalt additives," Journal of Testing and Evaluation, vol. 41, no. 1, pp. 141-147, 2013.

[33] A. Ameli, A. F Naeini, R Babagoli, and A Akbari, "Effects of anti-striping agents on performance of binder and stone matrix asphalt (SMA) mixtures containing polyphosphoric acid/styrene-butadiene rubber composite polymer blends and warm mixture additives," Journal of Thermoplastic Composite Materials, 2020.

[34] A. Yousefi, A. Behnood, A. Nowruzi, and H. Haghshenas, "Performance evaluation of asphalt mixtures containing warm mix asphalt (WMA) additives and reclaimed asphalt pavement (RAP)," Construction and Building Materials, vol. 268, Article ID 121200, 2021.

[35] H. Y. Katman, M. R. Ibrahim, M. R. Karim, N. S. Mashaan, and S. Koting, "Evaluation of permanent deformation of unmodified and rubber-reinforced SMA asphalt mixtures using dynamic creep test," Advances in Materials Science and Engineering, vol. 2015, Article ID 247149, 11 pages, 2015.

[36] M. Solaimanian, D. Anderson, and D. Hunter, "Evaluation of VESTENAMER reactive modifier in crumb rubber asphalt. Performance of asphalt binder and asphalt concrete," Modified by Ground Tire and Vestenamer-A Laboratory Study, vol. 379, 2003.

[37] G. Yadollahi and H. Sabbagh Mollahosseini, "Improving the performance of crumb rubber bitumen by means of poly phosphoric acid (PPA) and vestenamer additives,"
Construction and Building Materials, vol. 25, no. 7, pp. 3108-3116, 2011.

[38] M. Zarei, Z. Rahmani, M. Zahedi, and M. Nasrollahi, "Technical, economic, and environmental investigation of the effects of rubber powder additive on asphalt mixtures," Journal of Transportation Engineering, Part B: Pavements, vol. 146, no. 1, Article ID 04019039, 2020.

[39] M. Zarei, B. Mirbaha, F. Akbarinia et al., "Application of concordance analysis method (CA) for optimal selection of asphalt mixtures reinforced with rubber powder and carbon fiber," Electronic Journal of Structural Engineering, vol. 20, no. 1, pp. 53-62, 2020.

[40] M. J. Ayazi, A. Moniri, and P. Barghabany, "Moisture susceptibility of warm mixed-reclaimed asphalt pavement containing Sasobit and Zycotherm additives," Petroleum Science and Technology, vol. 35, no. 9, pp. 890-895, 2017.

[41] N. A. Awazhar, F. H. Khairuddin, S. Rahmad et al., "Engineering and leaching properties of asphalt binders modified with polyurethane and Cecabase additives for warm-mix asphalt application," Construction and Building Materials, vol. 238, Article ID 117699, 2020.

[42] S. N. A. Şahin and İ. Metin, "The effect of pawma addition on bitumen viscosity, penetration and softening point from warm mix asphalt additives," in Proceedings of the International Conference on Civil, Environmental, Geology and Mining Engineering, Trabzon, Turkey, 2019.

[43] S. Hosseinnezhad, S. F. Kabir, D. Oldham, M. Mousavi, and E. H. Fini, "Surface functionalization of rubber particles to reduce phase separation in rubberized asphalt for sustainable construction," Journal of Cleaner Production, vol. 225, pp. 82-89, 2019.

[44] K. Shatanawi, S. Biro, C. Thodesen, and S. Amirkhanian, "Effects of water activation of crumb rubber on the properties of crumb rubber-modified binders," International Journal of Pavement Engineering, vol. 10, no. 4, pp. 289-297, 2009.

[45] K. Beena and C. Bindu, "Influence of additives on the drain down characteristics of stone matrix asphalt mixtures," International Journal of Research in Engineering and Technology, vol. 3, no. 7, pp. 83-88, 2014.

[46] N. Kumar, S. Manimaran, and K. Sureshraja, "Drain down analysis of bituminous mix modified with natural fibre," International Journal of Innovations in Engineering and Technology (IJIET), pp. 2319-1058, 2016.

[47] V. Najafi Moghaddam Gilani, S. M. Hosseinian, D. Safari, and M. B. Movahhed, "Investigation of the impact of deicer materials on thermodynamic parameters and its relationship with moisture susceptibility in modified asphalt mixtures by carbon nanotube," Arabian Journal for Science and Engineering, vol. 2020, 2020.

[48] V. Najafi Moghaddam Gilani, S. M. Hosseinian, and M. Nikookar, "Presentation of a new deicer with the least moisture and fatigue failures in asphalt mixtures," Arabian Journal for Science and Engineering, 2021.

[49] G. H. Hamedi, M. R. Esmaeeli, V. Najafi Moghaddam Gilani, and S. M. Hosseinian, "The effect of aggregate-forming minerals on thermodynamic parameters using surface free energy concept and its relationship with the moisture susceptibility of asphalt mixtures," Advances in Civil Engineering, vol. 2021, Article ID 8818681, 15 pages, 2021.

[50] V. Najafi Moghaddam Gilani et al., "Presentation of predictive models for two-objective optimization of moisture and fatigue damages caused by deicers in asphalt mixtures," Journal of Testing and Evaluation, 2021, in Press. 
[51] AASHTO, Laboratory Evaluation of Modified Asphalt Systems, American Association of State Highway and Transportation Officials, Washington, DC, USA, 1993.

[52] C. Fang, X. Qiao, R. Yu et al., "Influence of modification process parameters on the properties of crumb rubber/EVA modified asphalt," Journal of Applied Polymer Science, vol. 133, no. 27, 2016.

[53] N. S. Mashaan and M. R. Karim, "Evaluation of permanent deformation of CRM-reinforced SMA and its correlation with dynamic stiffness and dynamic creep," The Scientific World Journal, vol. 2013, Article ID 981637, 7 pages, 2013.

[54] H. Ziari, H. Divandari, M. Moradi, and R. Babagoli, "Experimental investigation on the effect of fly ash on mechanical properties of polymer modified SMA," Journal of Transportation Research, vol. 14, no. 1, pp. 96-113, 2017.

[55] R. K. Padhan, A. A. Gupta, C. S. Mohanta, R. P. Badoni, and A. K. Bhatnagar, "Performance improvement of a crumb rubber modified bitumen using polyoctenamer and cross linking agent," Road Materials and Pavement Design, vol. 18, no. 4, pp. 999-1006, 2017.

[56] F. Zhang and C. Hu, "Physical and rheological properties of crumb rubber/styrene-butadiene-styrene compound modified asphalts," Polymer Composites, vol. 38, no. 9, pp. 1918-1927, 2017.

[57] Z. Leng, R. K. Padhan, and A. Sreeram, "Production of a sustainable paving material through chemical recycling of waste PET into crumb rubber modified asphalt," Journal of Cleaner Production, vol. 180, pp. 682-688, 2018.

[58] G.-X. Yu, Z.-M. Li, X.-L. Zhou, and C.-L. Li, "Crumb rubbermodified asphalt: microwave treatment effects," Petroleum Science and Technology, vol. 29, no. 4, pp. 411-417, 2011.

[59] P. Mirzababaei, "Effect of zycotherm on moisture susceptibility of warm mix asphalt mixtures prepared with different aggregate types and gradations," Construction and Building Materials, vol. 116, pp. 403-412, 2016.

[60] A. Mansourkhaki and A. Aghasi, "Performance of rubberized asphalt containing liquid nanomaterial anti-strip agent," Construction and Building Materials, vol. 214, pp. 468-474, 2019.

[61] H. Ziari, H. Divandari, M. Hajiloo, and A. Amini, "Investigating the effect of amorphous carbon powder on the moisture sensitivity, fatigue performance and rutting resistance of rubberized asphalt concrete mixtures," Construction and Building Materials, vol. 217, pp. 62-72, 2019. 